\title{
Ease of access is a principal factor in the frequency of paracetamol overdose
}

\author{
M O'Rourke, MR Garland', PA McCormick \\ Liver Unit and Department of Psychiatry', St Vincent's University Hospital, Dublin, Ireland
}

\begin{abstract}
Background In Ireland, 30\% of non-fatal overdoses involve paracetamol.

Aims To determine how and where patients obtained paracetamol, to assess awareness of toxicity and examine the relationship between dose and suicidal intent.
\end{abstract}

Methods A prospective study of patients admitted following a paracetamol overdose recording their reasons for using paracetamol, their knowledge of its toxicity and their suicidal intent scale (SIS).

Results Of 100 patients, $66 \%$ obtained paracetamol in non-pharmacy outlets, $82 \%$ cited ease of availability as the reason, $55 \%$ were aware of its toxicity, $31 \%$ of liver damage and $68 \%$ did not read the warning on packets. The mean number of tablets taken was 51.3 for males and 37.2 for females $(p<0.01)$. Males presented later than females for medical attention (12.5 versus seven hours $[p<0.02])$ and more males than females took alcohol $(p<0.03)$. The mean SIS score was 14.71 for males and 12.38 for females. There was a significant correlation between the SIS and the amount of paracetamol consumed $(r=0.28 ; p<0.01)$.

Conclusion The majority obtained paracetamol in local shops or at home. Knowledge of toxicity and the need for early antidote was poor. There was a significant relationship between suicidal intent and number of tablets consumed. Limiting availability could reduce number of overdoses.

\section{Introduction}

Paracetamol is a commonly used agent in self-poisoning and a frequent cause of hospital admission from poisoning in Ireland. ${ }^{1,2}$ Statistics compiled by the Irish National Suicide Research Foundation of hospital-treated parasuicide in the Southern and Mid-Western Health Boards show that 30\% of all non-fatal overdoses involve paracetamol. The increase in selfpoisoning with paracetamol is a cause of concern to the medical profession. ${ }^{1}$ In Ireland, the unrestricted availability of paracetamol has been criticised, ${ }^{1,3}$ particularly as paracetamol overdose is a significant cause of fulminant liver failure with a mortality rate of approximately $11 \%{ }^{4-6}$

Several studies ${ }^{711}$ have shown that misuse of paracetamol is associated with greater availability of the drug and poor understanding of the possible consequences. In spite of warnings about the dangers of overdosing with paracetamol, those who exceed the recommended dose often have poor understanding of its potentially lethal hepatotoxicity. One British study ${ }^{8}$ found that only $10 \%$ of patients hospitalised for overdose recognised hepatotoxicity as a potential danger, whereas another study ${ }^{10}$ found that more than $75 \%$ of those who took an overdose expected it to cause death.

In the UK, the introduction of restrictions governing the sale of paracetamol has been associated with a reduction in the incidence of paracetamol-induced liver failure. . $^{12,13}$ After legislation, the annual number of admissions with hepatic paracetamol poisoning to liver units declined by $30 \%$ compared with two years before legislation. ${ }^{14}$ Limiting the size of packs of paracetamol and salicylates sold over the counter has had substantial beneficial effects on the annual number of deaths from paracetamol poisoning and liver transplant rates. ${ }^{14}$

In Ireland, the introduction of the new regulations banning retailers from selling more than one pack of 12 standard strength $500 \mathrm{mg}$ paracetamol could have a beneficial impact on mortality and morbidity associated with paracetamol overdose. $^{15}$

We conducted a prospective study to determine how and where patients obtained paracetamol for overdose, their awareness of its toxicity and whether any relationship existed between alleged suicidal intent and amount consumed.

\section{Patients and methods \\ Study population}

Between August 1998 and July 2000, we identified patients admitted with paracetamol overdose to St Vincent's University Hospital, Dublin, either from the A\&E department daily logbook or the hepatology ward admissions log. St Vincent's University Hospital is a teaching hospital and is located in the East Coast Area Health Board. It serves a local catchment area with a population of 325,000 persons and is the National Centre for Liver Transplantation.

\section{Procedures}

During their hospital admission, suitable patients were approached and asked to complete study surveys. Data were collected by questionnaire, which was administered individually in an informal interview. The St Vincent's University Hospital Ethics Committee approved the study.

\section{Questionnaires}

Two questionnaires were used. The first asked how and where paracetamol was obtained, anticipated effects after overdose and if taken on impulse. Patients were asked to state the reasons that led them to seek medical attention and to estimate the number of hours from time of overdose to presentation for medical attention. A question asked about knowledge of safety information and if the 
warning label on the package was read prior to taking overdose, after overdose or not at all, and if they had taken alcohol with the overdose.

The second questionnaire was the suicidal intent scale (SIS) developed by Beck et al. ${ }^{16}$ This is a commonly used, psychometrically sound, observer-rated instrument which measures the declared degree of suicidal intent associated with an act of self-harm. It is a 15 item instrument, with each item scored as 0,1 or 2 , the higher the score (maximum: 30) the greater the degree of suicidal intent.

\section{Statistical analyses}

Results were analysed using the Statistical Package for the Social Sciences (SPSS for Windows) ${ }^{17}$ and the Instat Biostatistics Program version 2.05A (GraphPad Software, Inc. San Diego, CA, USA). Data are expressed as mean, standard deviation (SD) and/or standard error of the mean (SEM). t tests, Pearson's coefficient and chi-square were used as appropriate.

\section{Results}

During the study period, 134 patients were admitted with a paracetamol overdose. Ninety-six were primary admissions and four were tertiary referrals ( 34 patients were judged too ill by the attending medical staff to answer questionnaires or provide valid informed consent). All patients approached agreed to participate. The study was terminated when 100 patients were interviewed. The study sample consisted of 77 females, with a mean age of 27.9 years (SD 9.30; range 13-49) and 23 males with a mean age of 29.8 years (SD 10.35; range 18 to 59 ). We found that $60 \%$ of the study group had a psychiatric history or a depressive episode, $49 \%$ had taken a previous overdose and $47 \%$ additional drugs.

As can be seen from Table 1 , the majority of patients in this study had a poor understanding of the toxicity of paracetamol. The results of the analyses found that $16 / 23$ males (69\%) and $50 / 77$ females $(64 \%)$ obtained paracetamol in supermarkets, local shops or filling stations and 5/23 males (21\%) and $17 / 77$ females $(22 \%)$ had paracetamol in their home. A total of $19 / 23$ males $(81 \%)$ and $63 / 77$ females $(82 \%)$ reported ease of availability as a reason for taking paracetamol and $17 / 23$ males $(73 \%)$ and $53 / 77$ females $(68 \%)$ obtained it specifically for overdose. Only $55 \%$ of the study group, $17 / 23$ males $(73 \%)$ and $38 / 77$ females (49\%) were aware of the harmful effects of paracetamol. Less than one-third $(31 \%)$ said they anticipated liver damage after overdose. A high proportion (69\%) were unaware of the hepatotoxic effects of paracetamol. Even though $51 \%$ expected death after overdose, $42 \%$ unconsciousness, $33 \%$ nausea and vomiting, $54 \%$ said they took it on impulse and then regretted the event. Over half the patients $(56 \%)$ sought medical attention within four hours of overdose, but $15 \%$ presented more than 12 hours after overdose and risked missing the therapeutic window for antidote administration. The mean number of paracetamol tablets taken was 51.3 for males and 37.2 for females $(t=1.7$; $\mathrm{p}<0.01)$.

Analyses revealed a statistically significant difference between men and women in time to presentation for medical attention. The mean time was 12.5 hours (SEM 2.8) for males versus 7.05 hours (SEM 0.93) for females $(\mathrm{t}=4.2, \mathrm{p}<0.02)$. Pressure from others was cited as the main reason for seeking medical attention. The onset of physical symptoms prompted $12 / 23$ males $(52 \%)$ and $34 / 77$ females $(44 \%)$ to seek medical attention. The majority of patients $(68 \%)$ did not read the warning label prior to taking the overdose. Significantly more males $17 / 23(73 \%)$ than females $36 / 77$ (46\%) admitted to taking alcohol with the overdose $(\mathrm{p}<0.03)$.

A total of 72 patients completed the SIS ( 55 females, 17
Table 1. Descriptive data with questionnaire.

Responses $(n=100)$

\begin{tabular}{|c|c|c|}
\hline \multirow[t]{2}{*}{ Questionnaire responses } & \multicolumn{2}{|c|}{ Frequencies } \\
\hline & Males (23) & Females (77) \\
\hline \multicolumn{3}{|l|}{$\begin{array}{l}\text { Reasons for choosing } \\
\text { paracetamola }\end{array}$} \\
\hline Easily available & 19 & 63 \\
\hline Inexpensive & 4 & 16 \\
\hline Aware of harmful effects & 17 & 38 \\
\hline Obtained for overdose & 17 & 53 \\
\hline Taken on impulse & 14 & 40 \\
\hline \multicolumn{3}{|l|}{$\begin{array}{l}\text { How/where paracetamol was } \\
\text { obtained }\end{array}$} \\
\hline Supermarket & 7 & 29 \\
\hline Local shop & 6 & 15 \\
\hline Filling station & 3 & 6 \\
\hline Home & 5 & 17 \\
\hline Pharmacy & 1 & 8 \\
\hline Prescription & 1 & 2 \\
\hline \multicolumn{3}{|l|}{ Anticipated after ODa } \\
\hline Death & 15 & 36 \\
\hline Unconscious & 13 & 29 \\
\hline Nausea/vomiting & 8 & 25 \\
\hline Liver damage & 6 & 25 \\
\hline \multicolumn{3}{|l|}{$\begin{array}{l}\text { Factors which led patients to } \\
\text { seek medical attentiona }\end{array}$} \\
\hline Physical symptoms & 12 & 34 \\
\hline Pressure from others & 11 & 42 \\
\hline Other & 3 & 11 \\
\hline \multicolumn{3}{|l|}{ Read warning label } \\
\hline Prior to taking OD & 6 & 20 \\
\hline After OD & 2 & 4 \\
\hline Not at all & 15 & 53 \\
\hline Took alcohol with overdose & $17^{\mathrm{b}}$ & 36 \\
\hline
\end{tabular}

males). The mean suicidal intent score for males was 14.71 (SEM 1.45; range 5-29) and for females was 12.38 (SEM 0.70; range $2-24 ; \mathrm{p}=\mathrm{NS}$ ). A weak but statistically significant correlation was found between the amount of paracetamol consumed and the degree of suicidal intent $(\mathrm{r}=0.28 ; \mathrm{p}<0.01)$.

\section{Discussion}

This prospective survey provided detailed information about how and where patients obtained paracetamol for overdose, their knowledge of its toxicity and degree of suicidal intent associated with the event. We found that two-thirds of the study participants obtained paracetamol in supermarkets, local shops or filling stations. Ease of access was the most commonly given reason for choosing paracetamol. Our findings are consistent with other studies ${ }^{9-11}$ which show that the availability of paracetamol in large quantities contributes to its use in overdose. Limiting availability could prove an effective strategy for reducing the frequency of paracetamol overdoses ${ }^{18}$ and has been shown to work in the UK..$^{12-14}$

Making it more difficult for people acting on impulse or embroiled in a transient crisis to obtain large amounts of paracetamol, may give time for reflection and a change of mind. ${ }^{19}$ Unfortunately, avoidable deaths may still occur ${ }^{20}$ particularly as many patients underestimate the toxicity of paracetamol. $^{21}$

Given the safety information on the package, it is alarming to find that a high proportion of study participants were unaware of the hepatotoxic effects of paracetamol when taken in excess. In this study, more than half did not read the warning label on 
the packet and less than half of the patients were aware of the need to seek medical attention urgently if more than 24 tablets were ingested. Many who take paracetamol are unaware of its delayed effect and fail to seek medical attention in time to prevent liver failure. ${ }^{21}$ It appears that men more than women place themselves at increased risk before presenting for treatment after paracetamol overdose.22 In our study, we encountered more females following paracetamol overdose. However, males were more likely to take significantly larger amounts, delay longer before presentation and take the overdose with alcohol. This clustering of factors is associated with poor prognosis and has implications for harm reduction in education. Clearly, many cases of overdose are not associated with serious suicidal intent. When interviewed after overdose, we found study participants reported experiencing a low degree of suicidal intent at the time of overdose.

Our findings have implications for public health safety and highlight the need for an effective plan to reduce the availability of paracetamol in large amounts. The Report of the National Task Force on Suicide in $1998^{3}$ highlighted the need to reduce the availability of methods of self-harm, particularly as previous voluntary guidelines were only partially effective. ${ }^{1}$ However, ease of access may not be the only reason for frequency of paracetamol overdoses. Another factor may be low public awareness of the hepatotoxic effect of paracetamol, particularly when the recommended dose is exceeded. Our data suggest that existing warning labels on packages appear to have little effect. As recommended by the Irish Medicines Board in $1997^{23}$ in the revised conditions for the supply and sale of paracetamol, the package label and leaflet should emphasise early hospital treatment as well as the high efficacy of the antidote $^{24}$ in the event of overdosage. Ongoing research and surveillance are required to monitor the incidence of selfpoisoning with paracetamol and to evaluate prevention programmes.

\section{Acknowledgements}

We acknowledge the support of the Hospital Inpatient Inquiry Unit, St Vincent's University Hospital, Dublin, and the National Suicide Research Foundation. This study was part funded by a grant from the Health Research Board.

\section{References}

1. Laffoy M, Scallan E, Byrne G. Paracetamol availability and overdose in Ireland. Ir Med J 2001 (in press).

2. Malone K, McCormack G, Malone JP. Non-fatal deliberate self-poisoning in Dublin's north inner city - an overview. Ir Med J 1992; 85: 132-5.

3. Irish Department of Health and Children. Report on the National Task Force on Suicide, Government Publications, January 1998.

4. Matkin AJ, Wendon J, Williams R. A seven year experience of severe acetominophen-induced hepatotoxicity (1987-1993). Gastroenterology 1995; 109: 1907-16.

5. Schiodt FV, Atillasoy E, Shakil AO, Schiff ER, Caldwell C. Aetiology and outcome for 295 patients with acute liver failure in the United States. Liver Transpl Surg 1999; 5 (1): 29-34.

6. Garnier R, Bismuth C. Liver failure induced by paracetamol. BMJ 1993; 306: 718 .

7. Gazzard BG, Davis M, Spooner J, Williams R. Why do people use paracetamol for suicide? BMJ 1976: 1: 212-3.

8. Hawton K, Ware C, Misty H, Hewitt et al. Why patients choose paracetamol for self-poisoning and their knowledge of its dangers. BMJ 1995; 310-164.

9. Myers WC, Otto TA, Harris E, Diaco D, Moreno A. Acetaminophen overdose as a suicidal gesture: a survey of adolescents' knowledge of its potential for toxicity. J Am Acad Child Adolescent Psychiatry 1992; 31: 686-90.

10. Gilbertson RJ, Harris E, Pandey SK, Kelly P, Myers W. Paracetamol use, availability, and knowledge of toxicity among British and American adolescents. Archives of Disease in Childhood 1996; 75: 194-8.

11. Harris HE, Myers WC. Adolescent's misperceptions of the dangerousness of acetaminophen in overdose. Suicide Life Threat Behav 1997; 27(3): 2747.

12. Prince MI, Thomas SHL, James FW, Hudson M. Reduction in incidence of severe paracetamol poisoning. The Lancet 2000; 355: 2047-8.

13. Turvill JL, Burroughs AK, Moore KP. Change in occurrence of paracetamol overdose in UK after introduction of blister packs. The Lancet 2000; 355: 2048-9.

14. Hawton K, Townsend E, Deeks J et al. Effects of legislation restricting pack sizes of paracetamol and salicylate on self-poisoning in the United Kingdom: before and after study. BMJ 2001; 322: 1203-7.

15. Medicinal Products (Control of Paracetamol) Regulations 2001 (SI No 150 of 2001).

16. Beck AT, Beck R, Kovacs M. Classification of suicidal behaviours: Quantifying intent and medical lethality. Am J Psych 1975a; 132: 285-7.

17. Babbie E, Halley F. Adventures in Social Research, Data Analysis Using SPSS for Windows (Statistical Package for the Social Science). Published by Pine Forge Press, 1995. A Sage Publications Company, 2455 Teller Road, Thousand Oaks, California 91320.

18. Taylor SJ. Reducing paracetamol overdoses. BMJ 1997; 314: 750-1.

19. Bridger S, Henderson K, Gluckman E. Deaths from low dose paracetamol poisoning. BMJ 1998; 316: 1724-25.

20. Bray GP. Liver failure induced by paracetamol. Avoidable deaths still occur. BMJ 1993; 306: 157-8.

21 McNicholl BP. Toxicity awareness and unintended suicide in drug overdoses. Arc Emerg Med 1992; 9: 214-9.

22 Bradley MP, Nguyen-Van JS, Parson JCG. "Late Presenters" after paracetamol self-poisoning. J Epidemiol Public Health, 1998; 52: 762-3.

23 Drug Safety Newsletter; Notification of changes in availability of OTC medicines; Paracetamol. Irish Medicines Board. 1997; 4.

24 McCormick PA, Casey P, Barry P, Laffoy M, Treacy J. Delays in administration of acetylcysteine in paracetamol overdose. Ir Med J 2000; 93:3: $77-8$.

Correspondence to: Ms M O'Rourke, RGN MSc, The Liver Unit, St Vincent's University Hospital, Elm Park, Dublin 4, Ireland. Tel. (01) 209 4181; fax (01) 283 7724; email m.orourke@st-vincents.ie 